\title{
Efeito da época do ano e período do dia sobre os parâmetros fisiológicos de reprodutores caprinos no semi-árido paraibano ${ }^{1}$
}

\author{
Gustavo de A. Silva ${ }^{2}$, Bonifácio B. de Souza ${ }^{3}$, Carlos E. P. Alfaro ${ }^{4}$, Elisângela M. N. da Silva ${ }^{4}$, \\ Solange A. Azevedo ${ }^{3}$, Jéferson Azevedo Neto ${ }^{4} \&$ Rosangela M. N. da Silva ${ }^{3}$
}

\begin{abstract}
RESUMO
Objetivou-se, com este trabalho, verificar o efeito da época do ano e período do dia sobre os parâmetros fisiológicos de reprodutores caprinos mestiços de Anglo-Nubiana com caprinos sem padrão racial definido, no Semi-árido paraibano. Utilizaram-se 20 caprinos machos, distribuídos em um delineamento inteiramente casualizado no esquema fatorial $2 \times 2$, duas épocas: $E_{1}$, maio a agosto e $E_{2}$, setembro a dezembro, e dois turnos, manhã e tarde, repetidos no tempo, totalizando 80 parcelas. Para os parâmetros hematológicos estudou-se apenas o efeito da época do ano. Os parâmetros fisiológicos, temperatura retal e freqüência respiratória, foram influenciados $(P<0,01)$ pelo turno, enquanto a temperatura superficial sofreu influência $(P<0,01)$ de ambos os fatores, turno do dia e época do ano. Os parâmetros hematológicos, hemácias, hematócrito e volume globular médio, foram influenciados $(\mathrm{P}<0,05)$ pela época do ano. A pouca variação dos parâmetros fisiológicos de caprinos mestiços de Anglo-Nubiana com sem padrão racial definido, demonstra alto grau de adaptação à temperaturas elevadas. No período de maior temperatura a perda de calor através da forma evaporativa, respiração, determina a elevação do hematócrito e do volume globular médio.
\end{abstract}

Palavras-chave: ambiência animal, temperatura retal, freqüência respiratória, bioclimatologia animal

\section{Effect of year time and period of day on physiological parameters of reproductive goats in the semi-arid Paraiba}

\begin{abstract}
The objective of this work was to verify the effect of time of year and period of day on physiological parameters of reproductive Anglo-Nubiana crossbred goats with goats without a defined racial pattern race, in the semi-arid Paraiba. 20 male goats were used, allocated into a completely randomized design in a $2 \times 2$ factorial scheme, two periods: $E_{1}$, May to August, and $\mathrm{E}_{2}$, September to December, and two periods, morning and afternoon, repeated in time, totaling 80 plots. For the hematological parameters only the effect of time of year was studied. The physiological parameters, rectal temperature and respiratory frequency were influenced $(P<0.01)$ by the period, while the surface temperature $(S T)$ suffered influence $(P<0.01)$ of both factors, day period and time of year. The parameters hematological, erythrocyte (HE), hematocrit (HT) and medium globular volume $(M G V)$ were influenced $(P<0.05)$ by the time of the year. The little variation of the physiological parameters of Anglo-Nubiana crossbred goats without defined racial patlern demonstrates a high adaptation degree to high temperatures. During the period of higher temperature, the heat loss in the form of evaporation and respiration determines the elevation of the hematócrit and medium globular volume.
\end{abstract}

Key words: animal environment, rectal temperature, respiratory frequency, animal bioclimatology

1 Parte da dissertação de mestrado do primeiro autor, financiada pela CAPES/CNPq/ UFCG/Patos, PB ${ }^{2}$ CSTR/UFCG, Peregrino de Araújo n 15, CEP. 58701-010, Patos, PB, Fone:(83) 3422-1387. E-mail: gugavet2000@yahoo.com.br ${ }_{3}^{3}$ DMV/UFCG, Fone: (83) 3421-3397. E-mail: bonif@cstr.ufcg.edu.br, rmnsilva@bol.com.br, solangeufcg@yahoo.com.br

${ }^{4}$ DCV/UFCG, CEP. 58700-000, Patos, PB, C.P. 64, Fone: (83) 3421-3231. E-mail: elisangelamns@yahoo.com.br, jefersonaneto@yahoo.com.br 


\section{INTRODUÇÃO}

O Nordeste do Brasil ocupa uma área de 1.219.021,50 km², a qual representa $18,2 \%$ do território brasileiro. A região se caracteriza por sua vulnerabilidade às alterações do clima, com períodos irregulares de chuva e secas prolongadas, intensificados pelas elevadas temperaturas, altos níveis de insolação e evaporação durante todo o ano, o que interfere na produção de alimentos. Introduzidos pelos colonizadores, os caprinos se adaptaram às condições adversas do ambiente, o que favoreceu o crescimento do rebanho na região, atualmente com cerca de 8.930 .000 cabeças, correspondendo a $94 \%$ do efetivo nacional (FAO, 2003).

Apesar da boa adaptação dos caprinos às condições climáticas do Nordeste, a exploração desses animais predominantemente em regime de manejo extensivo, aliada aos cruzamentos desordenados, à baixa disponibilidade de forragens de boa qualidade durante boa parte do ano e à escassez de água, juntamente com as elevadas temperaturas e intensa radiação solar direta e indireta, contribuiu para o surgimento de animais, que ganharam em rusticidade e perderam em produtividade (Silanikove, 1992), mas, ao longo dos anos, o uso de tecnologias produtivas vem aumentando a expectativa de crescimento da produtividade, ressaltando-se a necessidade em se manter os animais adaptados às adversidades climáticas, para servirem como base aos programas de melhoramento, já que a interação entre animais e ambiente deve ser fortalecida, quando se busca maior eficiência na exploração pecuária, em virtude das variáveis fisiológicas poderem ser afetadas pelas variações climáticas, colocando em risco o aumento da produção.

Dentre as tecnologias introduzidas, o cruzamento entre raças nativas e exóticas foi uma das principais estratégias adotadas para o melhoramento caprino na região Nordeste, destacando-se, dentre as raças caprinas introduzidas, a Anglo-Nubiana, por ser de dupla aptidão, apresentar boa adaptação e ter maior potencial de produção em relação aos caprinos naturalizados, além de possuir mais rusticidade quando comparada com as demais raças importadas (Mello et al., 1996), características que podem ser bem observadas em seus mestiços com as raças nativas e os tipos sem padrão racial definido.

Portanto, avaliações dos efeitos climáticos sobre o comportamento fisiológico desses animais são imprescindíveis para o conhecimento da sua real capacidade adaptativa o que, do ponto de vista produtivo, tem grande importância, uma vez que em elevadas temperaturas a energia oriunda do metabolismo, que seria utilizada para o crescimento e produção, é desviada para a manutenção da temperatura do corpo, afetando negativamente a produtividade (Baêta \& Souza, 1997).

Nos animais homeotérmicos, a temperatura do corpo se mantém relativamente constante, devido ao balanço existente entre a quantidade de calor produzido e a quantidade de calor perdido, através de uma série de mecanismos de regulação térmica os quais incluem respostas fisiológicas e comportamentais ao ambiente; no entanto, quando os animais são expostos a uma temperatura ambiental elevada, acima da temperatura crítica superior, estão sujeitos a hipertermia, sendo necessário valem-se do sistema termorregulatório, através da vasodilatação cutânea, sudorese e do aumento da freqüência respiratória para manter a temperatura corporal (Baêta \& Souza, 1997) podendo chegar a um ponto em que o organismo animal será incapaz de controlar a sua própria temperatura, rompendo o equilíbrio homeostático e desencadeando o estresse calórico, razão pela qual a capacidade do animal resistir aos rigores do estresse calórico tem sido avaliada fisiologicamente por alterações na temperatura retal e freqüência respiratória, uma vez que são considerados os melhores indicadores de tolerância ao calor (Brown-Brandl et al., 2003).

A freqüência respiratória em caprinos apresenta valor médio de 25 movimentos respiratórios por minuto, variando entre 20 e 34 movimentos, podendo esses valores ser influenciados pelo trabalho muscular, temperatura ambiente, ingestão de alimentos, gestação, idade e tamanho do animal (Dukes \& Swenson, 1996).

De la Sota et al. (1996) afirmaram que, quando o animal é submetido à condições ambientais estressantes, suas funções fisiológicas, temperatura retal, freqüência respiratória, ingestão de alimentos, desvio de nutrientes, redução no crescimento e na resistência a doenças, bem como os parâmetros sanguíneos, são alterados.

Uribe-Velásquez et al. (2001) relataram que cabras alpinas, tanto em condições de termoneutralidade como sob influência de estresse em câmara bioclimatológica, apresentaram médias de temperatura retal, no turno da tarde, superiores às do período da manhã sendo que, nos animais sob estresse, os valores da temperatura retal foram superiores, devido a uma hipertermia temporária nesses animais. Para Ogebe et al. (1996) valores de temperatura retal e freqüência respiratória são influenciadas pelo sexo e pela estação do ano.

Os parâmetros hematológicos também têm sido utilizados mundialmente para avaliar o estado de saúde dos animais e como indicadores de estresse calórico (Paes et al., 2000); contudo, vários fatores devem ser levados em consideração, tais como: espécie, raça, sexo, idade, estado fisiológico e a hora do dia, uma vez que eles podem interferir nos valores de referência para a interpretação dos referidos parâmetros (Jain, 1993). Desta forma, os valores hematológicos obtidos para animais criados em determinada região não podem ser considerados valores de referência para animais de outra região, sem uma avaliação adequada (Birgel Júnior et al., 2001).

Silva et al. (2003b) relataram que o estresse por calor de longa duração pode reduzir o número de eritrócitos e o volume globular, levando a uma hemoconcentração, em função da perda de água pela evaporação. Kolb (1987) descreveu que a alimentação deficiente reduz a neoformação de eritrócitos e o valor do hematócrito. E como a hemoglobina representa aproximadamente $92,0 \%$ dos componentes dos eritrócitos, ocorre também redução da hemoglobina.

Ante as interferências climáticas sobre o desempenho produtivo dos animais, particularmente quando se consideram duas épocas do ano bem distintas, seca e chuvosa, no semiárido paraibano, torna-se necessário avaliar o efeito de fatores climáticos sobre os caprinos explorados na região, uma vez que a zona de termoneutralidade define limites de temperatura: temperaturas crítica superior e inferior, em que os ani- 
mais entram em estresse, em temperaturas acima da temperatura crítica superior e abaixo da temperatura crítica inferior, interferindo sobre a resposta fisiológica do animal.

Objetivou-se, com este trabalho estudar a influência de duas épocas do ano e do período do dia sobre os parâmetros fisiológicos de reprodutores caprinos, mestiços de AngloNubiana com sem padrão racial definido, no município de Patos, Semi-árido da Paraíba.

\section{MATERIAL E MÉTODOS}

O trabalho foi desenvolvido no Centro de Saúde e Tecnologia Rural (CSTR), da Universidade Federal de Campina Grande (UFCG), Campus de Patos, localizado na região Semi-árida do estado da Paraíba, que se caracteriza por apresentar um clima BSH, de acordo com Köppen, com temperatura anual média máxima de $32,9{ }^{\circ} \mathrm{C}$ e mínima de $20,8^{\circ} \mathrm{C}$. Foram utilizados 20 caprinos, reprodutores, com idade variando de dois a três anos, mestiços Ango-Nubiana com SPRD, distribuídos em um delineamento inteiramente casualizado, em esquema fatorial 2 x 2, duas épocas: $E_{1}$, maio a agosto, e $E_{2}$, setembro a dezembro, e dois turnos, manhã e tarde, repetidos no tempo, totalizando 80 parcelas. Para os parâmetros hematológicos estudou-se apenas o efeito de época.

Os animais foram mantidos, durante todo o período experimental, em regime de manejo intensivo, alojados em baias individuais, de madeira, com $2,5 \mathrm{~m}^{2}$ cada, dispostas no sentido leste-oeste, em galpão de alvenaria aberto nas laterais, com altura superior a $4,0 \mathrm{~m}$, piso de cimento e cobertura de telha de cimento amianto e receberam dieta ajustada para atender às exigências de mantença em proteína, energia, cálcio e fósforo, constituída de 31,0\% de feno de Tifton (Cynodon spp), $11,0 \%$ de farelo de soja, $15,0 \%$ de farelo de trigo, $41,0 \%$ de farelo de milho e $2,0 \%$ de suplemento mineral para caprinos, além de água e sal "ad libitum".

Inicialmente, os animais passaram oito semanas em período de adaptação à dieta e ao manejo, tempo em que foram vermifugados e avaliados clinicamente. Os parâmetros aferidos foram: fisiológicos, temperatura retal (TR), freqüência respiratória (FR) e temperatura superficial (TS); hematológicos, hemácias (HE), hemoglobina (HB), hematócrito (HT) e volume globular médio (VGM). Os fisiológicos foram observados duas vezes por semana, nos dois turnos, manhã e tarde, às 9:00 e às 15:00 h durante 30 dias na $E_{1}$ e na $E_{2}$ e, para os hematológicos, realizou-se uma coleta de sangue, em cada uma das épocas, para realização do eritrograma.

A TR foi mensurada através da introdução de um termômetro clínico veterinário, com escala até $44{ }^{\circ} \mathrm{C}$, diretamente no reto do animal, a uma profundidade de $5 \mathrm{~cm}$, pelo período de 2 min e o resultado expresso em graus centígrados. A FR foi obtida através da auscultação indireta das bulhas, com auxílio de estetoscópio flexível, na região laringo-traqueal, contando-se o número de movimentos durante 1 min e o resultado expresso em movimentos por minuto $\left(\mathrm{mov} \mathrm{min}^{-1}\right)$. A TS corresponde à média aritmética das temperaturas obtidas em oito regiões determinadas do corpo: temperatura superficial da fronte (TSF), do pescoço (TSP), do lombo (TSL), do costado (TSC), do ventre (TSV), da coxa (TSCx), da canela (TSCn) e do testículo (TST), com auxílio de termômetro infravermelho digital sem contato (ST3 - RAYTEK).

Para realização do eritrograma foram coletados $5 \mathrm{~mL}$ de sangue dos animais, através de venipunção da jugular, em tubos a vácuo (Vacuette, Creiner Bione, Vacuette do Brasil LTDA, Campinas São Paulo) com o anticoagulante etilenodiaminotetracético, sal dissódico (EDTA) a 10\%. A contagem global de HE foi realizada em câmara de Newbauer, usandose a solução de Gower como diluidor. Obteve-se o teor de HB através do método de cianometahemoglobina, com leitura por espectofotometria (Espectofotômetro Baush-Lomb Spectronic 20) a $525 \mathrm{~nm}$. Para determinação do HT utilizou-se do método do microhematócrito, durante $10 \mathrm{~min}$, e o VGM foi calculado pela fórmula de Wintrobe (Birgel, 1982).

Obtiveram-se as medições das variáveis ambientais diariamente, no período experimental, duas vezes ao dia, às 9:00 h e 15:00 h, com auxílio de termômetros de máxima e mínima (TMM), termômetro de bulbo seco (TBS), termômetro de bulbo úmido (TBU) e termômetro de globo negro (TGN), que foram instalados no interior das instalações, à altura dos animais. Calcularam-se, de posse desses dados, os valores do Índice de temperatura do globo negro e umidade (ITGU) e do índice de temperatura e umidade (THI), de acordo com as fórmulas: ITGU $=\mathrm{TGn}+0,36 \mathrm{Tpo}+41,5 \mathrm{e} \mathrm{THI}=0,72(\mathrm{Tbs}+$ Tbu) $+40,6$ descritas por Buffington et al. (1981) e Benício \& Souza (2001), respectivamente.

Os dados obtidos foram submetidos a análise de variância e as médias comparadas pelo teste de Tukey, utilizandose o programa (SAS, 1996).

\section{RESULTADOS E DISCUSSÃO}

\section{Variáveis ambientais}

As variáveis ambientais observadas durante o período experimental e os valores médios do ITGU e do THI, encontram-se na Tabela 1.

Tabela 1. Médias dos dados meteorológicos, temperatura de bulbo seco (TBS), temperatura de bulbo úmido (TBU), temperatura de globo negro (TGN), índice de temperatura e umidade (THI) e índice de temperatura do globo negro e umidade (ITGU) nas $\mathrm{E}_{1}$ e $\mathrm{E}_{2}$ e nos turnos da manhã e tarde, no ambiente experimental

\begin{tabular}{|c|c|c|c|c|c|c|c|c|c|c|}
\hline \multirow{2}{*}{ Épocas } & \multicolumn{5}{|c|}{ Turno da Manhã } & \multicolumn{5}{|c|}{ Turno da Tarde } \\
\hline & TBS & TBU & TGN & THI & ITGU & TBS & TBU & TGN & THI & ITGU \\
\hline$E_{1}$ & $28,17 \mathrm{Aa}$ & $21,19 \mathrm{Aa}$ & $28,94 \mathrm{Aa}$ & $76,14 \mathrm{Aa}$ & $77,30 \mathrm{Aa}$ & $32,77 \mathrm{Ab}$ & $22,01 \mathrm{Ab}$ & $33,81 \mathrm{Ab}$ & $80,04 \mathrm{Aa}$ & $81,55 \mathrm{Ab}$ \\
\hline $\mathrm{E}_{2}$ & $30,03 \mathrm{Ba}$ & $22,23 \mathrm{Ba}$ & $30,92 \mathrm{Ba}$ & $78,23 \mathrm{Ba}$ & $79,42 \mathrm{Ba}$ & $35,71 \mathrm{Bb}$ & $23,90 \mathrm{Bb}$ & $37,06 \mathrm{Bb}$ & $83,52 \mathrm{Bb}$ & $85,16 \mathrm{Bb}$ \\
\hline
\end{tabular}

Médias seguidas de letras diferentes maiúsculas na coluna e minúsculas na linha diferem estatisticamente pelo teste

$\mathrm{F}(\mathrm{P}<0,05)$ 
Houve interação significativa $(\mathrm{P}<0,05)$ entre época e turno para as variáveis TBS, TGN, THI e ITGU. Todas as variáveis ambientais diferiram estatisticamente $(\mathrm{P}<0,05)$ com relação à época e ao turno, sendo os maiores valores encontrados na $E_{2}$ e no turno da tarde.

As médias das temperaturas máxima e mínima nas $\mathrm{E}_{1}$ e $\mathrm{E}_{2}$ foram de 33,34 e 36,76 e de 22,69 e $23,80^{\circ} \mathrm{C}$, respectivamente. Os valores de temperaturas do bulbo seco à sombra, no turno da tarde nas $\mathrm{E}_{1}$ e $\mathrm{E}_{2}$, foram 32,77 e $35,71{ }^{\circ} \mathrm{C}$ respectivamente, valores estes que se apresentaram na $\mathrm{E}_{1}$ abaixo da temperatura máxima de conforto térmico para caprinos e na $E_{2}$, no turno da tarde, acima da temperatura máxima de conforto térmico, de acordo com a classificação de Lu (1989) que estabelece valores de 30 a $35^{\circ} \mathrm{C}$. Os valores médios do THI nas duas épocas e nos dois turnos, apesar de diferirem estatisticamente $(\mathrm{P}<0,05)$ apresentaram-se elevados e próximos aos valores do ITGU nos respectivos períodos o que se deve à pouca variação de TGN com relação à TBS, em virtude da condição de sombra do local onde foi desenvolvido o experimento, conforme demonstrado na Figura 1.

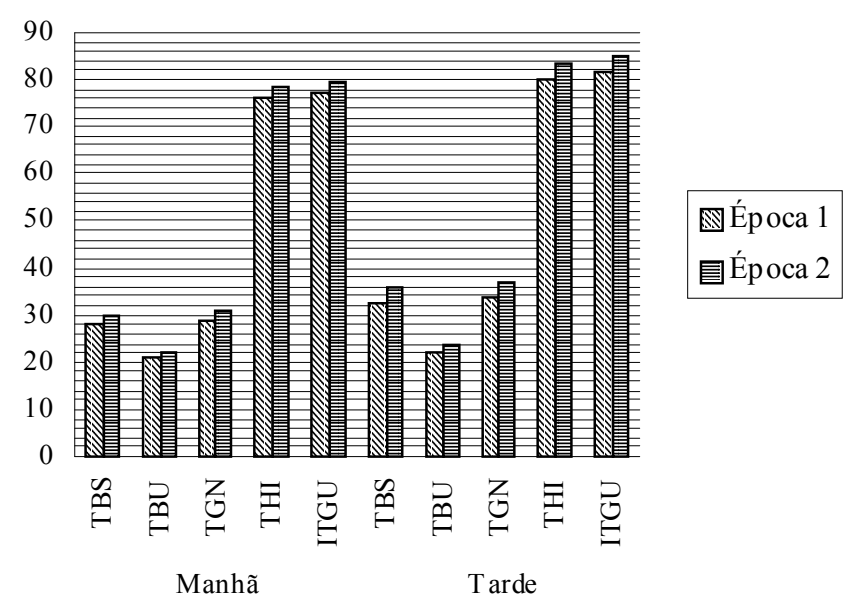

Figura 1. Comportamento das variáveis ambientais nos dois turnos nas $E_{1}$ e $E_{2}$

Embora na ausência de radiação direta os valores do ITGU no turno da tarde se apresentaram elevados, 81,55 e 85,16 na $E_{1}$ e $E_{2}$ respectivamente, os mesmos não podem ser considerados situação perigosa para caprinos mestiços de AngloNubiana com SPRD, uma vez que a TR se encontra dentro da normalidade demonstrando não estar havendo estocagem de calor e, ainda por não existir uma tabela de referência para o ITGU em caprinos, demonstrando uma maior capacidade de tolerância ao calor por esta espécie. Santos et al. (2005) ao trabalharem com caprinos nativos e exóticos na E1 no Semiárido paraibano encontraram um ITGU de 85,5 no turno da tarde, valor superior ao encontrado neste trabalho para a mesma época e período, o que para os autores demonstrou alta capacidade de adaptação. De acordo com National Weather Service - EUA, apud (Baêta, 1985) até 74 os valores do ITGU definem situação de conforto; de 74 a 78, situação de alerta; de 79 a 84, situação perigosa e acima de 84, emergência.

\section{Parâmetros fisiológicos}

Não houve interação significativa $(\mathrm{P}>0,01)$ entre os fatores época do ano e o turno. Os parâmetros TR e FR foram influenciados $(\mathrm{P}<0,01)$ pelo turno, enquanto que a TS sofreu influência $(\mathrm{P}<0,01)$ de ambos os fatores, cujas médias estão demonstradas na Tabela 2.

Tabela 2. Médias* dos parâmetros fisiológicos, temperatura retal (TR), freqüência respiratória (FR) e temperatura superficial (TS) de caprinos mestiços de Anglo-Nubiana com SPRD nas $E_{1}$ e $E_{2}$ e nos turnos manhã e tarde

\begin{tabular}{|c|c|c|c|}
\hline \multirow{2}{*}{ Fatores } & \multicolumn{3}{|c|}{ Parâmetros Fisiológicos } \\
\hline & $\operatorname{TR}\left({ }^{\circ} \mathrm{C}\right)$ & FR $\left(\operatorname{mov} \mathrm{min}^{-1}\right)$ & $\operatorname{TS}\left({ }^{\circ} \mathrm{C}\right)$ \\
\hline \multicolumn{4}{|l|}{ Épocas: } \\
\hline $\mathrm{E}_{1}$ & $39,1 \mathrm{~A}$ & $37,8 \mathrm{~A}$ & $31,0 \mathrm{~A}$ \\
\hline $\mathrm{E}_{2}$ & $39,1 \mathrm{~A}$ & $42,1 \mathrm{~A}$ & $31.8 \mathrm{~B}$ \\
\hline \multicolumn{4}{|l|}{ Turnos: } \\
\hline Manhã & $38,9 \mathrm{~A}$ & $30,3 \mathrm{~A}$ & $29,5 \mathrm{~A}$ \\
\hline Tarde & $39,3 \mathrm{~B}$ & $49,5 B$ & $33,3 \mathrm{~B}$ \\
\hline CV (\%) & 0,47 & 25,51 & 1,95 \\
\hline
\end{tabular}

Todos os parâmetros fisiológicos estudados apresentaram médias superiores no turno da tarde, o que pode ser explicado pelos valores mais elevados dos parâmetros térmicos ambientais estudados neste período, Tabela 1, associado à elevação da temperatura corpórea, provocada pelo ciclo nictemeral dos animais. Estes resultados estão de acordo com os encontrados por Silva et al. (2003a) quando estudaram TR, FR e TS de caprinos mestiços de Anglo-nubiana no Semi-árido paraibano na $E_{1}$. Medeiros et al. (1998) quando trabalharam com cabras Anglo-Nubiana e Pardo Alemã em ambientes com diferentes níveis de sombra e ao sol, também constataram aumento significativo dos parâmetros fisiológico TR, FR e FC, no turno da tarde, sendo que os animais que sofreram exposição direta ao sol apresentaram as médias mais elevadas para TR, em decorrência da carga térmica imposta pela radiação solar direta.

As médias da TR verificada nas $E_{1}$ e $E_{2}$ não diferiram estatisticamente $(\mathrm{P}>0,01)$ em virtude, sem dúvida, da proteção da cobertura do galpão, que evitou a incidência da radiação solar direta sobre os animais, porém as mesmas se apresentaram próximas à descrita por Arruda \& Pant (1985) que foi de $39,2^{\circ} \mathrm{C}$, quando trabalharam com caprinos em épocas semelhantes, e dentro dos valores de referência normais para caprinos adultos na sombra. De acordo com Baccari Júnior et al. (1996) a TR físiológica em caprinos varia de 38,5 a $40,0{ }^{\circ} \mathrm{C}$ e vários fatores são capazes de causar variações na temperatura corporal, entre as quais estão: idade, sexo, estação do ano, período do dia, exercício e ingestão e digestão de alimentos; por isto, a TR é considerada a medida que melhor representa a temperatura do núcleo corporal, além de ser bastante utilizada para verificar o grau de adaptabilidade dos animais, por ser considerada bom indicador de estresse calórico (Brown-Brandl et al., 2003). 
Acharya et al. (1995) notaram que, quando expostos à radiação solar direta, caprinos apresentaram valores superiores para TR, durante o período da tarde com relação ao período da manhã. Brasil et al. (2000) relataram que cabras Alpinas, tanto em condições de termoneutralidade como sob estresse térmico, apresentaram TR superior no turno da tarde o que, para os autores, ocorre em função das temperaturas serem mais elevadas nesse período e do próprio ciclo metabólico dos animais.

A FR apresentou-se acima da considerada fisiológica para a espécie, demonstrando que, embora na ausência de estresse, a temperatura ambiente elevada, principalmente no turno da tarde, interferiu, ativando o sistema termorregulatório, promovendo maior perda de calor, pela forma evaporativa através da respiração. Quando ocorre uma elevação acentuada da temperatura ambiente os mecanismos termorregulatórios são acionados aumentando a perda de calor na forma latente, através do aumento da FR e/ou da sudorese, na tentativa de manter a temperatura corporal dentro dos limites normais evitando a hipertermia. Brasil et al. (2000) trabalhando com caprinos, em condições de termoneutralidade e sob estresse térmico, verificaram que houve uma variação da FR com relação ao período do dia, sendo a média no turno da tarde 173,8 mov min $^{-1}$ superior ao turno da manhã 80,0. De acordo com Radostits et al. (2002) um aumento elevado da temperatura ambiente pode dobrar a freqüência respiratória normal dos animais.

Além da temperatura ambiente, a radiação solar também representa grande influência sobre a FR e TS, principalmente nos animais de pelagem escura, que absorvem maior quantidade de calor (Acharya et al., 1995).

Medeiros et al. (1998) trabalhando com caprinos confinados das raças Pardo Alemã e Anglo-Nubiana verificaram que a radiação solar interferiu, aumentando a FR dos animais. Souza et al. (2003) ao estudarem caprinos Moxotó, criados extensivamente, constataram a FR média de 59,2 mov min $^{-1}$ para $E_{1}$, valor superior ao encontrado neste trabalho com mestiços Anglo-Nubiana com SPRD 37,8 mov min $^{-1}$ em função, provavelmente, da radiação solar direta e da diferença entre raças.

A TS foi influenciada pelo turno e pela época, sendo mais elevada no turno da tarde e na $E_{2}$, demonstrando que, mesmo de forma indireta, a radiação afeta este parâmetro nos períodos de maior temperatura, concordando com Medeiros et al. (1998) e com os resultados encontrados por Silva et al. (2003a) quando estudaram a influência da época do ano e do turno sobre a referida variável. Segundo Habeeb et al. (1992) o redirecionamento do fluxo sanguíneo e a vasodilatação facilitam a dissipação de calor por mecanismos não evaporativos; condução, convecção e radiação, reduzindo a TS, porém, a eficácia desses mecanismos depende da diferença de temperatura entre o corpo do animal e o ambiente. Quando há uma diferença de temperatura aceitável, o excesso de calor é dissipado do corpo aquecido para o meio mais frio; do contrário, o animal terá que utilizar mecanismos evaporativos.

\section{Parâmetros hematológicos}

Os valores médios dos parâmetros hematológicos encontram-se na Tabela 3.

Tabela 3. Valores médios* de hemácias $(\mathrm{HE})$, hemoglobina $(\mathrm{HB})$, hematócrito $(\mathrm{HT})$ e volume globular médio (VGM) de caprinos mestiços de Anglo-Nubiana com SPRD nas $\mathrm{E}_{1} \mathrm{E}_{2}$ do Semi-árido paraibano

\begin{tabular}{ccccc}
\hline Épocas & $\mathbf{H E}\left(\mathbf{1 0}^{\mathbf{6}} \mathbf{~ m m}^{-3}\right)$ & $\mathbf{H B}\left(\mathbf{g ~ d l}^{-1}\right)$ & $\mathbf{H T}(\%)$ & $\mathbf{V G M}\left(\boldsymbol{\mu}^{3}\right)$ \\
$\mathrm{E}_{1}$ & $15,3 \mathrm{~A}$ & $9,4 \mathrm{~A}$ & $23,8 \mathrm{~A}$ & $15,5 \mathrm{~A}$ \\
$\mathrm{E}_{2}$ & $13,9 \mathrm{~B}$ & $8,9 \mathrm{~A}$ & $27,0 \mathrm{~B}$ & $19,2 \mathrm{~B}$ \\
\hline * Médias seguidas de letras diferentes &
\end{tabular}

$\mathrm{Na} \mathrm{E}_{1}$, o parâmetro $\mathrm{HE}$ apresentou valor superior $(\mathrm{P}<0,05)$ ao da $E_{2}$, sendo as médias observadas de 15,3 e $13,9 \times 10^{6}$ $\mathrm{mm}^{-3}$. Com relação a $\mathrm{HB}$, não se verificou efeito significativo $(\mathrm{P}>0,05)$ entre as épocas, o que está de acordo com os resultados encontrados por Jain (1993) e em discordância com Nunes et al. (2002), já que se esperava um valor superior para HB na época mais quente, devido à maior freqüência respiratória neste período e, desta forma, maior liberação de oxigênio via hemoglobina. Sabe-se que uma das funções da HB consiste no transporte de oxigênio dos pulmões para os diferentes tecidos e que, em situação de estresse, o valor da HB deve apresentar-se elevado, em função da maior da taxa de consumo de oxigênio; portanto, a ausência de diferença significativa $(\mathrm{P}>0,05)$ entre as épocas para HB demonstra que os animais não sofreram estresse severo, já que estavam confinados e protegidos da radiação solar direta.

$\mathrm{Na} \mathrm{E}_{2}$, os valores dos parâmetros HT e VGM, 27,0\% e 19,2, foram superiores $(\mathrm{P}<0,05)$ aos da $\mathrm{E}_{1}$. Segundo Dukes \& Swenson (1996), a variação do hematócrito e do volume globular depende da severidade da carga calórica imposta sobre o animal, podendo este estar aumentado em função de uma desidratação, em conseqüência da perda de líquidos por mecanismos evaporativos de dissipação de calor, ou mesmo diminuído em função de anemias, prenhez avançada e hemólise, porém, Lima (1983) estudando o volume globular de caprinos no Semi-árido paraibano, com faixa etária de 13 a 15 meses, não verificou diferenças significativas entre os períodos do dia, discordando dos resultados encontrados neste trabalho.

\section{CONCLUSÕES}

1. A pouca variação dos parâmetros fisiológicos em caprinos mestiços de Anglo-Nubiana com SPRD, demonstra alto grau de adaptação desses animais a temperaturas elevadas.

2. No período de maior temperatura, $\mathrm{E}_{2}$, a perda de calor através da forma evaporativa, respiração, determinou a elevação do hematócrito e volume globular médio.

R. Bras. Eng. Agríc. Ambiental, v.10, n.4, p.903-909, 2006. 


\section{LITERATURA CITADA}

Acharya, R.M.; Gupta, U.D.; Sehgal, J.P.; Singh, M. Coat characteristics of goats in relation to heat tolerance in the hot tropics. Small Ruminant Research, Amsterdam, v.18,n.4, p.245-248, 1995.

Arruda, F.A.V.; Pant, K.P. Freqüência respiratória em caprinos brancos e pretos de diferentes idades. Pesquisa Agropecuária Brasileira, Brasília, v.20, n.11, p.1351-1354, 1985.

Baccari Júnior, F.; Gayão, A.L.B.A.; Gottschalk, A.F. Metabolic rate and some physiological and production response of lactating Saanen goats during thermal stress. In: International congress of biometeorology, 14, 1996, Ljubjlana. Proceedings... Ljubjlana: ISB, 1996. p.119.

Baêta, F.C. Responses of lacting dairy cows to the combined affects of temperature, humidity and wind velocity in the warm season. Kansas city: University Missouri,1985. 218p. Tese Doutorado

Baêta, F.C.; Souza, C.F. Ambiência em edificações rurais conforto térmico.1.ed. Viçosa: UFV, 1997. 246p.

Benício, T.M.A.; Souza, B.B. Determinação do índice de conforto térmico para animais domésticos no município de $\mathrm{Pa}$ tos, PB. In: Encontro de Iniciação Científica da UFPB, 9, 2001, João Pessoa. Anais... João Pessoa: UFPB, 2001. CD Rom.

Birgel, E.H. Hematologia Clínica Veterinária. In: Birgel, E.H., Benesi, F.J. Patologia clínica veterinária. São Paulo: Sociedade Paulista de Medicina Veterinária, 1982. p.2-34.

Birgel Júnior, E.H.; D’angelino, J.L.; Benesi, F.J.; Birgel, E.H. Valores de referência do eritrograma de bovinos da raça Jersey criados no estado de São Paulo. Arquivo Brasileiro de Médicina Veterinária e Zootecnia, Belo Horizonte v.53, n.2, p.164-171, 2001.

Brasil, L.H.A.; Wechesler, F.S.; Baccari Júnior, F.; Gonçalves, H.C.; Bonassi, I.A. Efeitos do estressee térmico sobre a produção, composição química do leite e respostas termorreguladoras de cabras da raça Alpina. Revista Brasileira de Zootecnia, Viçosa, v.29, n.6, p.1632-1641, 2000.

Brown-Brandl, T.M.; Nienaber, J.A.; Eigenberg, R.A.; Hahn, G.L.; Campos, O.F.; Silva, J.F.C.; Milagres, J.C.; Sampaio, A.O. Comportamento de ovinos submetido a três níveis de temperatura ambiente. Revista Ceres, Viçosa, v.20, p.231242, 2003.

Buffington, D.E.; Collazo-Arocho, A; Canton, G.H.; Pitt, D. Black Globe-Humidity index (BGHI) as Comfort equation for dairy cows. Transactions of the Asae, St. Joseph, v. 24, p.711-713, 1981.

De la Sota, R.L.; Risco, C.A.; Moreira, F.; DeLorenzo, M.A. Efficacy of a timed insemination program in dairy cows during summer heat stress. Journal Animal Science, Champaing, v.74, p.133, 1996.
Dukes, H.H.; Swenson, H.J. Fisiologia dos animais domésticos. 11.ed. Rio de Janeiro: Guanabara 1996, 856p.

FAO. Dados estatísticos do Brasil e agronegócios. http:// www.fao.org/woicend, portal/statistic em asp. 05 Set. 2003.

Jain, N.C. Essentials of veterinary hematology. Philadelphia: Lea \& Febiger, 1993, 417p.

Habeeb, A.L.M.; Maray, I.F.M.; Kamal, T.H. Farm animals and the environment. Cambridge: CAB, 1992. 428p.

Kolb. Fisiologia veterinária. 4.ed. Rio de Janeiro: Guanabara Koogan, 1987, 612p.

Lima, S.M. Correlação da temperatura corporal e volume globular de caprinos Capra hircus L. normais da raça Moxotó. Recife: UFRPE, 1983. 68p. Dissertação Mestrado

Lu, C.D. Effects of heat stress on goat production. Small Ruminant Research, Amsterdam, v.2, n.2, p.151-162, 1989.

Medeiros, L.F.; Scherer, P.O.; Vieira, D.H.; Sousa, J.C.D. Freqüência respiratória e cardíaca de caprinos de diferentes raças e idades. In: Reunião da Sociedade Brasileira de Zootecnia, 35, 1998, Botucatu, Anais... Botucatu: SBZ, 1998. CD Rom

Mello, A.A.; Barros, N.N.; Alves, J.U. Características de crescimento na fase de aleitamento em caprinos das raças Anglo-Nubiana, Pardo Alpina e Saanen em Sobral, Ceará. Centro Nacional de Pesquisa de Caprinos. Sobral: EMBRAPA, 1996. p.79-82. Relatório Técnico 1987-1995

Nunes, A.S.; Barbosa, O.R.; Sakaguti, E.S.; Sakuno, M.L.D.; Araújo, M.F.T.E.; Silva, C.P. Efeito de dois regimes de suplementação e dois sistemas de produção, nos constituintes sangüíneos de cabras Saanen durante a lactação. Revista Brasileira de Zootecnia, Viçosa, v.31, n.3, p.1245-1250, 2002.

Ogebe, P.O.; Ogunmodede, B.K.; Mcdowell. Behavioral and physiological responses of Nigerian dwarf goats to seasonal changes of the humid tropics. Small Ruminant Research, Amsterdam, v.22, n.1, p.213-217, 1996.

Paes, P.R., Barioni, G., Fonteque, J.R. Comparação dos valores hematológicos entre caprinos fêmeas da raça Parda-Alpina de diferentes faixas etárias. Veterinária Notícias, Uberlândia, v.6, n.1, p.43-49, 2000.

Radostits, O.M.; Gay, C.C.; Blood, D.C.; Hinchcliff, K.W. Clínica veterinária. Um tratado de doenças dos bovinos, ovinos, suínos, caprinos e eqüinos. 9.ed. Rio de Janeiro: Guanabara Koogan, 2002. 1736p.

Santos, F.C.B.; Souza, B.B.; Alfaro, C.E.P.; Cézar, M. F.; Pimenta Filho, E.C.; Acosta, A.A.A.; Santos, J.R.S. Adaptabilidade de caprinos exóticos e naturalizados ao clima semi-árido do Nordeste brasileiro. Ciência e Agrotecnológia, Lavras, v.29, n.1, p.142-149, 2005.

SAS Institute. SAS User's: Statistics. 6.ed. Cary: North Carolina, 1996. 956p.

Silanikove, N. Effects of water scarcity and hot environment on appetite and digestion in ruminants: a review. Livestook Production Science, Amsterdam, v.30, p.175-194, 1992. 
Silva, G.A.; Souza, B.B.; Silva, E.M.N.; Silva, A.K.B.; Acosta, A.A.A.; Azevedo, S.A.; Neto, J.A. Determinação de parâmetros fisiológicos e gradientes térmicos de caprinos no semi-árido paraibano. In: Simpósio Internacional Sobre o Agronegócio da Caprinocultura Leiteira, 1, e Simpósio Internacional Sobre Caprinos e Ovinos de Corte, 2, 2003, João Pessoa. Anais... João Pessoa: EMEPA-PB, 2003a. CD Rom.

Silva, R.M.N.; Souza, B.B.; Arcoverde, M.C.P.; Tavares, G.P.; Marinho, M.L.; Benício, T.M.A. Efeito da época do ano sobre os parâmetros hematológicos de bovinos Sindi no Semi-Árido. In: Reunião Anual da Sociedade Brasileira de Zootecnia, 40, 2003, Santa Maria. Anais... Santa Maria: SBZ, 2003b. CD Rom.
Souza, B.B.; Brito Segundo, E.A.; Santos, J.R.S.; Ferreira, M.C.; Batista, H.J.C.; Santos, A.M. Avaliação do comportamento fisiológico de caprinos Moxotó e ovinos Santa Inês sob às condições Semi-árida, através de respostas termorregulatórias e gradientes térmicos. In: Congresso Pernambucano de Medicina Veterinária, 5, e Seminário Nordestino de Caprino-Ovinocultura, 6, 2003, Recife. Anais... Recife: UFRPE, 2003. CD Rom.

Uribe-Velásquez, L.F.; Oba, E.; Brasil, L.H.A.; Sousa, F.N.; Wechsler, F.S. Efeitos do estresse térmico nas concentrações plasmáticas de progesterona $\left(\mathrm{P}_{4}\right)$ e estradiol 17-b $\left(E_{2}\right)$ e temperatura retal em cabras da raça Pardo Alpina. Revista Brasileira de Zootecnia, Viçosa, v.30, n.2, p.388393, 2001. 